\title{
Asking the Patient About Patient-Centered Medical Homes: A Qualitative Analysis
}

\author{
Jaya Aysola, $M D, M P H^{1,2}$, Rachel M. Werner, $M D, P h D^{1,2,3}$, Shimrit Keddem, $\mathrm{MS}^{4}$, Richard SoRelle, $\mathrm{BS}^{4}$, \\ and Judy A. Shea, $P h D^{7}$
}

\begin{abstract}
'Division of General Internal Medicine, Department of Medicine, Perelman School of Medicine, University of Pennsylvania, Philadelphia, PA, USA; ${ }^{2}$ Leonard Davis Institute of Health Economics, University of Pennsylvania, Philadelphia, PA, USA; ${ }^{3}$ Center for Health Equity Research and Promotion, Philadelphia VA Medical Center, Philadelphia, PA, USA; ${ }^{4}$ Mixed Methods Research Lab (MMRL), Department of Family Medicine \& Community Health, University of Pennsylvania, Philadelphia, PA, USA.
\end{abstract}

BACKGROUND: What patients perceive and experience within a patient-centered medical home (PCMH) is an understudied area, and to date, the patient perspective has not been an integral component of existing $\mathrm{PCMH}$ measurement standards. However, upcoming guidelines necessitate the use of patient-reported experiences and satisfaction in evaluations of practice and provider performance.

OBJECTIVE: To characterize patients' experiences with care after $\mathrm{PCMH}$ adoption and their understanding and perceptions of the PCMH model and its key components, and to compare responses by degree of practice-level PCMH adoption and patient race/ethnicity.

DESIGN: Qualitative study.

PARTICIPANTS: Adult patients with diabetes and/or hypertension $(n=48)$.

APPROACH: We surveyed and ranked all PCMH adult primary care practices affiliated with one academic medical center with at least three providers $(n=23)$, using an instrument quantifying the degree of $\mathrm{PCMH}$ adoption. We purposively sampled minority and non-minority patients from the four highest-ranked and four lowest-ranked $\mathrm{PCMH}$-adopting practices to determine whether responses varied by degree of $\mathrm{PCMH}$ adoption or patient race/ethnicity. We conducted semi-structured telephone interviews with patients about their experiences with care and their perceptions and understanding of key $\mathrm{PCMH}$ domains. Interviews were recorded, transcribed, and imported into NVivo 10 for coding and analysis, using a modified grounded theory approach.

KEY RESULTS: We found that patients uniformly lacked awareness of the PCMH concept, and the vast majority perceived no PCMH-related structural changes, regardless of the degree of practice-reported PCMH adoption or the patient's race/ethnicity. Despite this lack of awareness, patients overwhelmingly reported positive relationships with their provider and positive overall experiences. CONCLUSIONS: As we continue to redesign primary care delivery with an emphasis on patient experience measures as performance metrics, we need to better understand what, if any, aspects of practice structure relate to patient experience and satisfaction with care.

Received November 17, 2014

Revised March 6, 2015

Accepted March 18, 2015

Published online April 16, 2015
KEY WORDS: Patient-centered care; Primary care redesign; Health care delivery; Health services research; Health policy.

J Gen Intern Med 30(10): 1461-7

DOI: $10.1007 /$ s 11606-015-3312-8

(C) Society of General Internal Medicine 2015

\section{INTRODUCTION}

The concept of the patient-centered medical home (PCMH) has gained support over the past decade from multiple stakeholders interested in strengthening the primary care delivery system, with the goal of providing high-quality, cost-effective, patient-centered care. ${ }^{1-3}$ In 2008, the National Committee for Quality Assurance (NCQA) proposed operational standards to recognize medical practices as patient-centered medical homes, which have emerged as the most commonly used set of standards. To date, however, there is no set of standards that utilizes patient-reported data to evaluate whether practices are achieving stated goals and adhering to the principles of the $\mathrm{PCMH}^{4}{ }^{4}$ Despite this fact, upcoming guidelines under the Affordable Care Act will require the inclusion of patientreported experience and satisfaction metrics in evaluations of primary care practice and provider performance. ${ }^{5}$

What patients perceive and experience within a PCMH model is an understudied area, with limited information on whether patient perceptions vary by practice characteristics reflecting the degree of PCMH adoption. Moreover, there is limited evidence thus far that PCMH improves existing racial/ethnic disparities in primary care. ${ }^{6-8}$ We do not know whether patient perceptions and experiences with PCMH differ by patient race/ethnicity, which is important for ensuring that the PCMH model provides equitable high-quality care. Therefore, we sought to characterize patient experiences with care after the adoption of PCMH, and their perceptions of the overall PCMH model and its key components, and to compare responses by patient race/ethnicity and the degree of practice-reported PCMH adoption.

\section{METHODS}

We conducted 48 semi-structured telephone interviews of patients from NCQA-recognized PCMH practices at the 
University of Pennsylvania Health System (UPHS) from November 2013 to April 2014. To determine whether patient responses varied by either the degree of PCMH adoption by a practice or the race/ethnicity of the patient, we purposively sampled to identify 48 respondents comprising 4 groups of 12 patients, representing the following: minority patients at highPCMH-adopting practices, non-minority patients at highPCMH-adopting practices, minority patients at low-PCMHadopting practices, and non-minority patients at low-PCMHadopting practices. Sampling details are further described below. The Institutional Review Board of the University of Pennsylvania approved this study protocol.

\section{Sampling and Recruitment}

Primary Care Practice Selection. Recruitment began by identifying all primary care practices affiliated with UPHS that served adult patients, had three or more providers, and had completed the NCQA PCMH recognition process, for a total of 23 eligible practices. At all eligible sites, practice managers or designees completed the Safety Net Medical Home Scale (SHCHS), a validated survey to quantify a practice's degree of PCMH adoption. ${ }^{9,10}$ The survey was designed to capture elements pertinent to serving diverse socioeconomic populations in a variety of primary care settings, and not exclusively safety-net clinics. ${ }^{9,10}$ We scored and ranked practices on the degree of PCMH adoption using a scoring algorithm accompanying the survey that produces a total medical home score (scale of 0 to 100) based on the average of six domains: access and communication, patient tracking and registry, care management, test and referral tracking, quality improvement, and external coordination. Further survey and scoring algorithms are detailed elsewhere. ${ }^{11}$ Among UPHS practices, overall PCMH adoption scores for all 23 eligible practices ranged from 28.4 to 71.6 , with a mean score of 57.6 and standard deviation of 9.2. We selected the four highest- and four lowest-scoring practices, representing high and low PCMH adopters, from which to recruit patients. Table 1 depicts the differences in mean scores for the six

Table 1 PCMH Domain and Overall Scores by High- and LowAdopting PCMH Practices

\begin{tabular}{|c|c|c|c|}
\hline \multirow[t]{2}{*}{ PCMH domains } & $\begin{array}{l}\text { High } \\
\text { PCMH } \\
\text { adopters }\end{array}$ & $\begin{array}{l}\text { Low } \\
\text { PCMH } \\
\text { adopters }\end{array}$ & \multirow[t]{2}{*}{$\begin{array}{l}P \\
\text { value }^{a}\end{array}$} \\
\hline & \multicolumn{2}{|c|}{$\begin{array}{l}\text { Mean scores } \\
\text { (standard deviation) }\end{array}$} & \\
\hline $\begin{array}{l}\text { Access and } \\
\text { communication }\end{array}$ & $79.6(4.6)$ & $62(22.2)$ & 0.09 \\
\hline $\begin{array}{l}\text { Patient tracking and } \\
\text { registry }\end{array}$ & $68.7(8)$ & $31.2(17.2)$ & 0.003 \\
\hline Care management & $63.5(4)$ & $40.6(9.2)$ & 0.002 \\
\hline Test and referral tracking & $43.8(4.2)$ & $30.2(14.1)$ & 0.06 \\
\hline Quality improvement & $64.6(14.2)$ & $36.1(13)$ & 0.01 \\
\hline External coordination & $85.9(5.7)$ & $54.7(21.9)$ & 0.02 \\
\hline Overall PCMH adoption & $67.7(2.7)$ & $42.5(9.6)$ & 0.001 \\
\hline
\end{tabular}

${ }^{a}$ t tests to assess statistical difference in mean scores between groups
PCMH domains and overall adoption between these highand low-PCMH-adopting practices.

Patient Respondent Selection. We selected minority and nonminority patients from the eight practices identified above, employing a non-proportional quota sampling strategy. ${ }^{12} \mathrm{We}$ identified potential respondents from the practice-based registry of adult patients who met the following eligibility criteria: had a diagnosis of hypertension or diabetes, were seen at their clinic in the past 12 months, and were English-speaking. We focused on patients with at least one chronic condition, hypertension and/or diabetes, in order to target a patient population more likely to use primary care services and potentially benefit from PCMHs. We categorized minority patients as those who self-identified as Hispanic/Latino, black/African American, or Native American/Pacific Islander, and non-minority patients as those who self-identified as non-Hispanic white/Caucasian. Of the 591 potential respondents, 127 could not be reached via telephone, 60 refused to participate, and 34 did not meet eligibility criteria. Of the remaining 370 potential respondents, we selected the first 48 who agreed to participate with informed consent.

\section{Data Collection}

We used a semi-structured interview guide including both open-ended items and highly structured, Likert-scaled survey questions. An interdisciplinary research team of experts in qualitative methods and primary care created the guide to assess respondents' experiences with delivery of care at their practices post-PCMH adoption and their perceptions and understanding of the overall PCMH model and key components. Questions were centered on the following PCMH domains: patient-provider relationship, shared decision-making, teambased and coordinated care, electronic health records, and enhanced access to care. Respondents were told up front in the interview to focus their responses on any problems that they had encountered or any changes they had experienced with care delivery at their primary care practice. Trained research assistants from the Mixed Methods Research Lab of the Department of Family Medicine and Community Health at the University of Pennsylvania ${ }^{13}$ conducted the semistructured telephone interviews, each lasting approximately $30 \mathrm{~min}$. During the interview, we asked respondents to report age, race/ethnicity, length of time at the practice, and length of time with the provider. Each respondent received a \$25 incentive upon completion of the interview.

\section{Data Analysis}

Interviews were audio-recorded and transcribed by an independent transcription agency. Transcripts were stripped of personally identifiable information and imported into NVivo $10^{14}$ for coding and analysis. Our authors, comprising experts in qualitative research and content experts in PCMH and primary care processes, met routinely to design and execute the study. We 
applied elements of grounded theory analysis to explore the data by simultaneous data collection and analysis, conducting continuous comparison across cases, and constructing codes based on concepts emerging organically from the data. The codebook contained ideas that emerged directly from the data as well as a priori constructs focused on the domains and intended goals of the PCMH model. We tested the codebook on the first ten transcripts and iteratively refined and restructured it to fit the data. Coding was performed by two trained research assistants. We used SPSS version 22.0 to quantify inter-rater reliability or the degree of agreement between the two coders in a subset of ten transcripts ( $21 \%$ of total sample). The degree of agreement, or kappa, ranged from 0.62 to 1 , with a median kappa of 1 , or perfect agreement. All coding disagreements were resolved by consensus, with authors present during the coding meetings. Once all transcripts were coded into broad categories, each broad code was further deconstructed into emergent subcategories to assess patterns across the experiences of all respondents as well as between each of our sampling categories, patients from high- versus low-PCMH-adopting practices, and racial/ethnic minority versus non-Hispanic whites. In addition, we explored differences in participant responses by other demographic and clinical characteristics.

\section{RESULTS}

About $46 \%$ of respondents self-identified as African American, $44 \%$ were between the ages of 41 and 60 , and $56 \%$ were female. Sixty-one percent of respondents were diagnosed as having high blood pressure, $8 \%$ had a diagnosis of diabetes, and $31 \%$ had been diagnosed as having both conditions. The median length of time that respondents had been at their PCP's practice was 7 years. and the median length of time that respondents had been seeing a particular PCP was 4 years. Table 2 provides a summary of respondent characteristics.

Table 2 Respondent Characteristics

\begin{tabular}{ll}
\hline \hline Characteristic & Respondents ${ }^{\mathbf{1}, \text { no. (\%) }}$ \\
\hline Race/ethnicity & $1(2)$ \\
Asian & $22(46)$ \\
Black/African American & $23(48)$ \\
Caucasian/White Non-Hispanic & $2(4)$ \\
Hispanic & $6(13)$ \\
Age & $21(44)$ \\
$21-40$ & $17(35)$ \\
$41-60$ & $4(8)$ \\
$61-80$ & $27(56)$ \\
$81+$ & $21(44)$ \\
Gender & $29(61)$ \\
Female & $4(8)$ \\
Male & $15(31)$ \\
Chronic condition & Median years \\
HTN & 7 \\
Diabetes & 4 \\
Both & \\
Length of time at clinic & \\
Length of time with provider & \\
\hline${ }^{\prime} N=48$ respondents &
\end{tabular}

Participant responses to the semi-structured interviews were categorized into the following themes: 1) their overall experiences with care at the clinic post-PCMH adoption and 2) their understanding and perceptions of the PCMH model and key domains, namely shared decision-making, team-based care and care coordination, electronic medical records, and access to medical care.

There were no consistent patterns or differences in participant responses by demographic or clinical characteristics - for example, those with diabetes versus hypertension versus both. Importantly, no differences were found based on selfidentified racial/ethnic categories or between high- and lowPCMH-adopting practices for any of the themes detailed below.

\section{Overall Experience with Care}

Respondents were all asked to describe their general experiences of care at the clinic. Overwhelmingly, responses indicated positive assessments and centered on their experiences and relationship with their PCP. For example:

"Well... I have a real nice doctor... She's very compassionate. She's a good person, you know... I feel like I could talk to her about anything." (Participant 48851)

Interestingly, any challenges with access, team-based care, or care coordination did not diminish respondents' overall satisfaction with care so long as their relationship with their PCP was solid. For example, respondents would relay problems, followed by positive statements about the doctor:

"I'm satisfied in general. I have a little qualm about the laboratory stuff, but the doctor, no. The doctor is excellent." (Participant 22035)

The vast majority of respondents reported positive relationships with their PCPs. Providers that were viewed favorably were considered reliable, medically adept, professional, and having agreeable personalities. In addition, respondents attributed positive relationships to PCPs who expressed genuine concern and were engaged in their patients' personal and medical well-being. The provider relationship appeared to influence respondents' overall experience as well as their perceptions on specific PCMH domains.

\section{Understanding and View of PCMH (Table 3)}

When asked directly, none of the respondents were familiar with the PCMH model, and all were initially unaware that their practices were PCMHs. Several expressed confusion about the model and its components, often related to a lack of familiarity with the concept or misunderstanding it, e.g. "Where they come to your house?" (Participant 14997) Ten respondents felt that the $\mathrm{PCMH}$ model description represented the care 
Table 3 Respondent Views of the PCMH Model

\begin{tabular}{|c|c|c|}
\hline Theme & Representative quote & No. $(\%)^{\mathrm{a}}$ \\
\hline $\begin{array}{l}\text { Supportive of } \\
\text { PCMH or } \\
\text { supportive with } \\
\text { reservations }\end{array}$ & $\begin{array}{l}\text { "I support this type of care because } \\
\text { it's great. I think, because, with } \\
\text { everyone's hectic schedule, } \\
\text { being able to offer the hours } \\
\text { and the convenience is really } \\
\text { beneficial to not just the client, } \\
\text { but also the doctor in retaining } \\
\text { their patients... and I think it's } \\
\text { just important to have a doctor } \\
\text { you see regularly that } \\
\text { understands your needs and } \\
\text { works towards better health."- } \\
\text { (Participant 63780) } \\
\text { "I think it is fine. It sounds very } \\
\text { ambitious though...It's expecting } \\
\text { an awful lot from our doctors, } \\
\text { isn't it?"-(Participant 57567) }\end{array}$ & $36(80)$ \\
\hline $\begin{array}{l}\text { PCMH reflective } \\
\text { of current care }\end{array}$ & $\begin{array}{l}\text { "I already have that sort of } \\
\text { situation with my provider, but I } \\
\text { never knew that terminology."- } \\
\text { (Participant 14968) }\end{array}$ & $10(22)$ \\
\hline $\begin{array}{l}\text { PCMH model not } \\
\text { applicable to me }\end{array}$ & $\begin{array}{l}\text { "At this point, as far as I'm } \\
\text { concerned, I don't really need } \\
\text { that type of care yet...No, I'm } \\
\text { still kind of able to do for } \\
\text { myself."-(Participant } 53230)\end{array}$ & $8(18)$ \\
\hline $\begin{array}{l}\text { Confused or } \\
\text { unsure about } \\
\text { PCMH model }\end{array}$ & $\begin{array}{l}\text { “Thoughts? I guess it sounds like } \\
\text { it's a good thing. I mean I } \\
\text { haven't really-I don't know. I } \\
\text { haven't seen it in action or } \\
\text { anything, but I guess it's all } \\
\text { right. I really don't know how } \\
\text { to answer that one."- } \\
\text { (Participant 14980) }\end{array}$ & $7(16)$ \\
\hline $\begin{array}{l}\text { PCMH is flavor } \\
\text { of the month }\end{array}$ & $\begin{array}{l}\text { "I regard, even the characterization } \\
\text { as patient-centered whatever, } \\
\text { whatever it is, as being, frankly, } \\
\text { the flavor of the month that } \\
\text { some consultant has sold you } \\
\text { guys. And so that's what is now } \\
\text { being done, and it'll be } \\
\text { succeeded by something else } \\
\text { someday."-(Participant 14993) }\end{array}$ & $2(4)$ \\
\hline
\end{tabular}

${ }^{a} N=45$ respondents provided usable responses. Respondents did express multiple valid views of PCMH, and categories above were not mutually exclusive.

they received, but did not originally connect the care with a specific model or initially provided inaccurate descriptions of a PCMH. The majority of individuals, even after hearing the description of the PCMH model, did not connect the model to the care they received at their practices.

After hearing a description of the PCMH model, more than half of respondents expressed either support of the model overall or support with some reservations. Supportive respondents described a variety of benefits of $\mathrm{PCMH}$, ranging from efficiency of care for complex conditions to an improved understanding between patients and providers. Some cited reservations, including questioning whether the model would hinder after-hours appointment availability or their ability to maintain continuity with their provider. Others expressed concerns over the applicability of PCMH to their situation or care needs. Some respondents noted that while they supported the idea in theory, they would have to experience it to truly assess its benefits. Lastly, two individuals viewed the model negatively, describing PCMH as a short-lived trend or endeavor lacking substance or impact.

\section{Experiences with Key PCMH Domains (Table 4)}

We found no discernable pattern between the respondents' experiences of care and the changes that practices reported they had made in the key PCMH domains below.

Shared Decision-Making. Respondents often described shared decision-making by specifying who should be engaged in discussions around medical treatment and medication decisions. Many believed that medical decision-making should primarily involve the patient and their doctor; however, some focused on the involvement of other stakeholders, such as family members and medical professionals. Notably, eight respondents did not reference themselves as a part of the shared decision-making process.

Respondents generally expressed a feeling of ownership of their medical decisions, yet largely relied on the expertise and advice of their PCP. Most articulated a sense of complete trust and comfort with their doctor's recommendation. Respondents who expressed having good rapport with their PCP were more likely to make suggestions or voice their opinions. Some respondents claimed that they participated in shared decision-making, without ever questioning or having interest in questioning their doctor's advice. Others stated that they felt unqualified to participate in medical decisions, as they were not medical professionals.

Team-Based Care. Respondents often attributed team member roles to their general office/clinic functions rather than specific job titles, such as noting individuals who took their vitals, fielded their calls or e-mails, handled paperwork and sign in/ sign out procedures, made appointments, and managed prescription refills. Importantly, almost all non-medically focused staff appeared to be viewed as secondary to the patient's PCP in terms of their role in overall patient care.

Care Coordination. Discussions centered on care coordination after receiving specialist care or after an acute medical event. While some described phone calls or electronic communication between their PCP and other providers, respondents were just as likely to describe not actually knowing how their PCP received information from specialists or other outside providers, but felt it was occurring. The majority of respondents did not report any difficulties with care coordination.

Electronic Medical Records (EMR). The majority of respondents viewed EMR favorably and saw its benefits in record keeping, improving communication, and care 
Table 4 Respondent Experiences with Key PCMH Domains

\begin{tabular}{|c|c|}
\hline PCMH domain & Representative quotes \\
\hline Shared decision-making & $\begin{array}{l}\text { "Well, I'll say it like this. It's like having a child, and you let them think they're making the decision, but the whole } \\
\text { time you know what they're gonna do because you're gonna tell them what to do. So it's like-I'm not a doctor. } \\
\text { If I knew what to take to make me get better, I wouldn't go to a doctor. I'd just go get it. But he has my best care } \\
\text { in mind and he does take good care of me and my wife, so he gives us options."-(Participant 57596) } \\
\text { "Yeah, in the end run, it's my problem and it's my health and my body, so if I have any objections or any questions } \\
\text { in the back of my mind, I'm not going to take the thing until I discussed with the doctor. If he clears up the little } \\
\text { things in my mind, well, then I'm happy and I take the medicine. And I've been happy with my medications and } \\
\text { I do take them."-(Participant } 22035 \text { ) } \\
\text { "Well, I haven't-- I haven't had any reason to say no, you know, if she recommends something. I think that she } \\
\text { does a good job, so far as my care is concerned." -(Participant 14949) }\end{array}$ \\
\hline Team-based care & $\begin{array}{l}\text { "Who helps with my care? All that works there. I think the crew is efficient. The lab technician is very efficient. } \\
\text { The aides that take the blood pressures, and whatever else, and they're very efficient."-(Participant 14985) }\end{array}$ \\
\hline Care coordination & $\begin{array}{l}\text { "Well, I feel like he [Doctor] was informed about it, because with the office called me to say would you come in, } \\
\text { because I had to see my surgeon at } 2 \text { weeks, and then go to see him [Doctor]... I was happy that they called me. } \\
\text { It was probably [Doctor's assistant] that called me, I think, and said we were aware that you had your } \\
\text { gallbladder out and would you call and make an appointment. And I think that's how it happened."-(Participant } \\
61316 \text { ) }\end{array}$ \\
\hline Electronic health records & $\begin{array}{l}\text { "I think it's great, only because now when I go see other doctors, they can pull it up on their computer or they can } \\
\text { see what the last notes that was made on me, so they would know where I'm at."-(Participant 48884) } \\
\text { "I haven't had that great of a concern other than hopefully the wrong people don't get into it. The people will- just } \\
\text { the everyday neighbors or anybody can get into your records. Or people that know you and work in a specific } \\
\text { place may decide to just go into your records. Yeah, I'm concerned about that."-(Participant 14985) } \\
\text { "I am somewhat not comfortable with it. I think they should be able to spend more time speaking to me instead of } \\
\text { typing in so much. But I don't mind."- (Participant 48792) }\end{array}$ \\
\hline Access to care & \\
\hline Scheduling appointments & $\begin{array}{l}\text { "I was able to always get an appointment regardless of whatever time fit my schedule... So I really like that office } \\
\text { because they do work around my schedule."-(Participant 63780) } \\
\text { "I can't get an appointment for maybe a week or a month, she's always booked up, and I don't like to see other } \\
\text { doctors, so that's why I guess I can say it's kind of hard getting an appointment with her unless I'm extremely } \\
\text { sick, they'll fit me in, something like that. But the whole time on the phone is horrible. They put you on hold, } \\
\text { and sometimes even they don't come back. It just hangs up."-(Participant 48806) }\end{array}$ \\
\hline $\begin{array}{l}\text { Communication between } \\
\text { appointments }\end{array}$ & $\begin{array}{l}\text { "Well, if I have any questions I can always call and leave a message, you know, and the doctor will call me back."- } \\
\text { (Participant 14949) } \\
\text { "E-mail... So I use that to communicate with the doctor." (Participant 14967) }\end{array}$ \\
\hline
\end{tabular}

coordination. Fourteen respondents expressed some concerns with EMR, the majority of which centered on information security and privacy, with the next most common relating to a concern that the use of the EMR would hinder their provider's ability to listen effectively while typing.

Access to Care. Respondents commonly referenced both positive and negative experiences in accessing care over time. The most common challenges encountered included difficulties scheduling appointments due to provider availability, difficulty reaching front desk staff, and wait times on phones, as well as accessing specialty care outside the practice. The majority felt they were able to easily communicate with their doctor between appointments via phone or e-mail.

\section{DISCUSSION}

In summary, our study examined patients' understanding and perceptions of care within PCMHs, and whether their experiences varied based on the degree of $\mathrm{PCMH}$ practice adoption or because the respondent was a racial/ethnic minority. We found that the overwhelming majority of respondents were unaware of PCMH concepts and the fact that their practice was a PCMH, regardless of the degree of PCMH adoption or their race/ethnicity. Moreover, this lack of understanding did not seem to affect experiences with care, which appeared to be dictated by respondents' overwhelmingly positive relationships with their providers.

In addition, we found no discernable pattern between respondents' experiences of care and the vast majority of reported changes made by practices in adopting the PCMH model. For example, respondents often perceived changes in access to care, both for better and for worse, irrespective of the practice's reported efforts in implementing structural processes that improved access. We propose three possible reasons for this finding. The first could be the lack of effective dissemination of PCMH principles to all staff throughout the practice. For example, in our study, we surveyed practice management to assess the degree to which practices adopted PCMH standards, yet for domains such as enhanced access and care coordination, patients' experiences may relate more to the front desk staff's steadfastness to these principles than to practice leadership's perceptions. If those directly involved in patient scheduling and referrals consistently adhere to PCMH-related policies, patients may be more likely to perceive the benefits. Currently, practice administrators or designated personnel report on the practice's policies in order to be recognized by the NCQA as a PCMH. However, there is a lack of knowledge on how such practice policy translates into the daily realities of 
practice operations. With any administrative policy requiring a change in practice structure and work flow, the degree of adoption is influenced by several organizational factors, including size and culture, and not merely the amount of time elapsed since implementation. ${ }^{15,16}$ A greater understanding is needed of the organizational factors influencing a practice's degree of PCMH adoption, including the awareness and commitment not only of practice leadership and primary care providers, but of all employees. ${ }^{17-19}$

A second potential reason for the lack of perception among respondents of structural changes intended to benefit them is the targeted population. Although practices have adopted PCMH standards uniformly for all patients, for our study, we chose to focus on patients that had at least one chronic condition, namely, diabetes and/or hypertension. While all respondents lacked an understanding of what PCMH was, when it was described to them, several did not perceive their need for such a model. This sentiment echoes a proposed notion that rather than instituting primary care redesign for all, practices implementing the PCMH model should direct efforts towards a select few with greater needs. ${ }^{20,21}$ How practices best define this target population warrants further inquiry, as our study suggests that enlisting those with either hypertension or diabetes or both may not be adequate. Other possibilities include targeting patients with poorly controlled chronic disease or those with complex conditions and a lack of social support, or directing efforts towards high-cost utilizers such as patients with repeated hospital readmissions. ${ }^{20-22}$

Third, the changes that practices adopt and report on to become PCMH models may not drive overall patient experience. We found that the relationship with the primary care provider uniformly drove patients' overall care experience. While these findings are consistent with prior work, ${ }^{23-27}$ what is unique to our study is the context in which this occurred. As practices adopt PCMH standards calling for team-based care and greater patient agency in decision-making and care management, what appears to matter almost exclusively to the patients is their relationship with their PCP. Discussions around PCMH adoption have centered on the need to change provider culture, ${ }^{28,29}$ but less noted is the need to change the expectations of the patient, or consumer culture. The traditional provider-centric paradigm continues to dominate patient experience, as our findings further substantiate. The question raised by our results is how to shift the PCMH model towards transforming that ideology for patients while supporting the relational aspects of care that they value most.

The lack of a distinct pattern in participant responses by race/ethnicity may reflect a future challenge in interpreting patient perspectives on outpatient care experiences. Prior literature demonstrates a positive response tendency in consumer health-related surveys among non-Hispanic black compared to non-Hispanic white respondents, and may explain our findings. ${ }^{30,31}$ Participants in our study provided overwhelmingly positive responses, possibly due to selection bias, which may also explain the lack of differences by race/ethnicity.
Patients' interpretations of the PCMH and its domains often appear to differ in both practice and theory from definitions utilized by the medical community. For example, many respondents questioned the necessity and value of PCMH, without recognizing that they were already participating in the PCMH model of care. Moreover, many respondents voiced the importance of shared decision-making, claiming that they were participating in it, while also expressing no interest in questioning their PCP on their treatment plans. As we move forward with primary care redesign efforts that emphasize engaging patients not only in managing their health, but also in providing feedback on ways to improve delivery ${ }^{18}$ a unified understanding among all stakeholders of the terms and concepts used to describe our efforts is paramount.

\section{LIMITATIONS}

Our study had limitations. These findings may lack generalizability, as we conducted the study in one network of practices. However, UPHS primary care practices are a diverse group of suburban and urban practices in New Jersey and Pennsylvania. Moreover, after reaching thematic saturation, we continued to sample by practice and patient characteristics to ensure the diversity of our sample and to examine responses stratified by key characteristics. We interviewed only English-speaking patients, and while we oversampled minorities, the perspectives of patients who were not fluent in English were not represented. Our findings may be subject to selection bias, as the patients who agreed to participate in these interviews may have represented differing views from those who declined. However, our study employed patient registries to recruit patients; thus, unlike visit-triggered interviews or surveys, we attempted to garner the perspectives of a broader set of patients affiliated with the practice outside the immediate clinical encounter.

\section{CONCLUSIONS}

Patient-centeredness is the cornerstone of the medical home model, with evidence to support its importance in utilization of the PCMH and quality of care. ${ }^{6,32,33}$ Medical homes can be reliably patient-centered only if robust methods are used to incorporate patients' experiences in PCMH implementation and evaluation. This study underscores the role that patient perspectives can play in the assessment of practice initiatives in primary care redesign. It illustrates the importance of the provider patient relationship over all other aspects of care delivery, and highlights the need to determine how to preserve this relationship as practices adopt a team-based approach and incorporate EMR and further technology to communicate with patients and coordinate care. Lastly, as we redesign primary care delivery with an emphasis on patient experience 
measures as performance metrics, these findings highlight the need to determine what aspects of the practice structure actually relate to patient experience and satisfaction with care.

Acknowledgments: Contributors: We would like to thank Dr. Peter Cronholm, MD, MSCE, and Kate Golden, MA, from the Mixed Methods Research Laboratory for their contributions to this study.

Financial Disclosure: Jaya Aysola was funded by an AHRQ PCOR Institutional Award (K12 HSO21706-01) for the duration of this study.

Prior Presentations: An abstract of this study was an oral presentation at the Hamolsky Award Finalist Session, Society of General Internal Medicine Annual Meeting, on April 24, 2014 in San Diego.

Conflict of Interest: The authors declare that they do not have a conflict of interest. The funders had no role in the design or conduct of the study; the collection, management, analysis, or interpretation of the data; or the preparation, review, or approval of the manuscript.

Corresponding Author: Jaya Aysola, MD, MPH; Division of General Internal Medicine, Department of Medicine, Perelman School of MedicineUniversity of Pennsylvania, Philadelphia, PA, USA (e-mail: jaysola@upenn.edu).

\section{REFERENCES}

1. Sia C, Tonniges TF, Osterhus E, Taba S. History of the medical home concept. Pediatrics. 2004;113(5 Suppl):1473-8.

2. American Academy of Pediatrics. Ad hoc task force on definition of the medical home: the medical home. Pediatrics. 1992;90(5):774.

3. Werner RM, Duggan M, Duey K, Zhu J, Stuart EA. The patient-centered medical home: an evaluation of a single private payer demonstration in New Jersey. Med Care. 2013;51(6):487-93.

4. Burton RADKJ, Berenson RA. Patient-centered medical home recognition tools: a comparison of ten surveys' content and operational details: The Urban Institute, Health Policy Center 2011 May 2011.

5. Protection P, Act AC. Patient protection and affordable care act. Public Law. 2010:111-48.

6. Aysola J, Bitton A, Zaslavsky AM, Ayanian JZ. Quality and equity of primary care with patient-centered medical homes: results from a national survey. Med Care. 2013;51(1):68-77. doi:10.1097/MLR.0b013e318270bb0d.

7. Jackson GL, Powers BJ, Chatterjee R, Bettger JP, Kemper AR, Hasselblad V, et al. The patient-centered medical home a systematic review. Ann Intern Med. 2013;158(3):169-78.

8. PCORI-Facilitators-Barriers-Providing-Patient-Centered-Chronic-DiseaseCare-120613.pdf. 2014.

9. Birnberg JM, Drum ML, Huang ES, Casalino LP, Lewis SE, Vable AM, et al. Development of a safety net medical home scale for clinics. J Gen Intern Med. 2011;26(12):1418-25. doi:10.1007/s11606-0111767-9.

10. Nocon RS, Sharma R, Birnberg JM, Ngo-Metzger Q, Lee SM, Chin MH. Association between patient-centered medical home rating and operating cost at federally funded health centers. JAMA $J$ Am Med Assoc. 2012;308(1):60-6. doi:10.1001/jama.2012.7048.

11. Safety Net Medical Home Scale (HCHS) with Exact Questions and Scoring Algorithm* - safety-net-medical-home-scalefinal722.pdf 2011. http://www.commonwealthfund.org/ /media/files/publications/other/2011/safety-net-medical-home-scalefinal722.pdf?la=en. Accessed March 32015.

12. Gobo G. Sampling, representativeness. Qualitative research practice. 2004:435-56.
13. Mixed Methods Research Lab / Perelman School of Medicine at the University of Pennsylvania. 2014. http://www.med.upenn.edu/mmrl/. Accessed 7/29/14.

14. NVivo qualitative data analysis software. 10 ed: QSR International Pty Ltd; 2012

15. Kimberly JR, Evanisko MJ. Organizational innovation: the influence of individual, organizational, and contextual factors on hospital adoption of technological and administrative innovations. Acad Manag J. 1981;24(4):689-713.

16. Rogers EM. Diffusion of innovations: Simon and Schuster; 2010.

17. Reid RJ, Fishman PA, Yu O, Ross TR, Tufano JT, Soman MP, et al. Patient-centered medical home demonstration: a prospective, quasiexperimental, before and after evaluation. Am J Manag Care. 2009; 15(9):e71-87.

18. Han E, Hudson Scholle S, Morton S, Bechtel C, Kessler R. Survey shows that fewer than a third of patient-centered medical home practices engage patients in quality improvement. Health Aff. 2013;32(2):368-75. doi:10. 1377/hlthaff.2012.1183.

19. Jaen CR, Ferrer RL, Miller WL, Palmer RF, Wood R, Davila M, et al. Patient outcomes at 26 months in the patient-centered medical home National Demonstration Project. Ann Fam Med. 2010;8(Suppl 1):S57-67. doi:10.1370/afm.1121. S92.

20. Kern LM, Dhopeshwarkar RV, Edwards A, Kaushal R. Patient experience over time in patient-centered medical homes. Am J Manag Care. 2013;19(5):403-10.

21. Heyworth L, Bitton A, Lipsitz SR, Schilling T, Schiff GD, Bates DW, et al. Patient-centered medical home transformation with payment reform: patient experience outcomes. Am J Manag Care. 2014;20(1):782-5.

22. Williams JW, Jackson GL, Powers BJ, Chatterjee R, Bettger JP, Kemper AR, et al. Closing the quality gap: revisiting the state of the science (vol. 2: the patient-centered medical home). Evid Rep Technol Assess. 2012;208(2): 1-210.

23. Grazier KL, Richardson WC, Martin DP, Diehr P. Factors affecting choice of health care plans. Health Serv Res. 1986;20(6 Pt 1):659-82.

24. Dorr Goold S, Lipkin M Jr. The doctor-patient relationship: challenges, opportunities, and strategies. J Gen Intern Med. 1999;14(Suppl 1):S26-33.

25. Cooper-Patrick L, Gallo JJ, Gonzales JJ, Vu HT, Powe NR, Nelson C, et al. Race, gender, and partnership in the patient-physician relationship. JAMA J Am Med Assoc. 1999;282(6):583-9.

26. Stewart MA. Effective physician-patient communication and health outcomes: a review. CMAJ. 1995;152(9):1423-33.

27. Keating NL, Green DC, Kao AC, Gazmararian JA, Wu VY, Cleary PD. How are patients' specific ambulatory care experiences related to trust, satisfaction, and considering changing physicians? J Gen Intern Med. 2002;17(1):29-39.

28. Nutting PA, Crabtree BF, McDaniel RR. Small primary care practices face four hurdles-including a physician-centric mind-set-in becoming medical homes. Health Aff. 2012;31(11):2417-22. doi:10.1377/ hlthaff.2011.0974.

29. Rosenthal MB, Friedberg MW, Singer SJ, Eastman D, Li Z, Schneider EC. Effect of a multipayer patient-centered medical home on health care utilization and quality: the Rhode Island chronic care sustainability initiative pilot program. JAMA Intern Med. 2013;173(20):1907-13. doi:10. 1001/jamainternmed.2013.10063.

30. Murray-Garcia JL, Selby JV, Schmittdiel J, Grumbach K, Quesenberry CP Jr. Racial and ethnic differences in a patient survey: patients' values, ratings, and reports regarding physician primary care performance in a large health maintenance organization. Med Care. 2000;38(3):300-10.

31. Dayton E, Zhan C, Sangl J, Darby C, Moy E. Racial and ethnic differences in patient assessments of interactions with providers: disparities or measurement biases? Am J Med Qual. 2006;21(2):109-14.

32. Aysola J, Orav EJ, Ayanian JZ. Neighborhood characteristics associated with access to patient-centered medical homes for children. Health Aff Proj Hope. 2011:30(11):2080-9. doi:10.1377/hlthaff.2011.0656.

33. Gray BM, Weng W, Holmboe ES. An assessment of patient-based and practice infrastructure-based measures of the patient-centered medical home: do we need to ask the patient? Health Serv Res. 2012;47(1pt1):4-21. doi:10.1111/j.1475-6773.2011.01302.x 